\title{
A COMPUTER SIMULATION MODEL OF A PRIVATE RAILWAY SYSTEM
}

\section{A. BROOMHEAD}

Pr.Eng., B.Sc(Eng), C.Eng., M.I.C.E., M.S.A.I.C.E.

Director of McClintock and Skinner Inc., 5 Girton Road, PARKTOHH, 2193.

\section{ABSTRACT}

The paper describes an operational study of a private railway system in the Transvaal. The main objective of the study was to recommend the minimum requirements for railway lines, locomotives and wagons and an economic, safe and reliable operating method for the proposed traffic levels, controlled by a remote signalling system. A survey of locomotive and train activities was undertaken to measure actual system activity times. The railway system was successfully modelled using the Firm's simulated tain haul programme and Hocus language The reaulting proposals showed a large capital saving, in the order of 100 times the study cost, below previously estimated capital costs. 


\section{INRRODUCTIOA}

\section{Background}

The proposed expansion of the Mine will result in four shafts feeding reef to three reduction plants. These shafts and plancs are ridely separated, and are connected by an extensive railway gystem consisting of about $35 \mathrm{~km}$ of single track and $35 \mathrm{~km}$ of sidings. Fifty daily scheduled reef train movements will occur in each direction when the new development is completed. A further two or three un-scheduled store trains per day will run during normal working hours between reef trains.

The existing railway network is complex with many opposing train movements. Control of the present operating systes is provided by two-way radio contact between the locomotive drivers and a central controller who memorises the location, direction and destination of crains with the assistance of $a \log$ sheet and $l i g h t$ panel, which the controller illuminates manually. The system is not fail safe and a number of accidents have occured. In a move to eliminate these safety hazards, the consequential loss of time and money, and to improve efficiençy, the Mine Management commissioned McClintock and Skinner Inc. to undertake an operating study, and to make recommendations regarding the installation of a signalling system. The study objective was to invertigate and report on the existing rail operating system, and the future one when the current extensions were completed. It was also necessary to make recomendations on the number of locomotives and wagons required to successfully operate the system. Any sections of running lines that needed to be doubled, or siding staging capacity to be increased were to be identified.

\section{Data collection}

The first step was to collect actual operating times for all the activities within the train "life cycles". These times were taken from the train controllers daily log sheets and compared with the expected norms. Where marked deviations occured attempts were made to obtain explanations, which were generally unsatisfactory, probably because the enquiries were made too long after the event. A new $\log$ sheet format was 
prepared and issued to the train controllers. Recordings were made over a two week period which improyed the confidence in the data. The two secs of results were selectively combined and the unacceptably high and low train running times vere eliminated.

\section{Dat a Analyạis}

The sets of collected data for each activity were analysed using the Firm's computer statistics progranme to yield the mean, standard deviation and associated normal distribution, histogram and Chi-square test for closeness of fit to the normal distribution. A typical set of activities for trains travelling from Shaft $A$ to the reduction sorks, Plant $A$, is given in Table 1 with the mean and standard deviation. Figure 1 shows a typical result from the computerised statistical analysis programe.

\section{Data Validation}

The running, refuelling, de-ashing, watering, loading and unloading $t$ imes were checked against our expectations for traffic of this nature. It was found that some of the running times appeared to be excessively long and it was decided to check these using the Firm's train run simulation programme. The simulat ion times proved to be considerably shorter than those reflected by the log sheets. Random checks were made at the mine with observers riding on the footplate of the locomotives, and the simulated times were verified. It was concluded that the data derived from the train controllers log sheets included additional time and delays not directly associated with the train schedules.

\section{TRAIN HAUL SIMULATIOA PROGRAMRE}

\section{Int roduct ion}

The problems as sociated with the simulation of a locomotive hauling a rake of wagons are both complex and numerous, involving the combination of adhesion, rolling, and curve resistances wich all have a vide range of values and depend upon the condition of the track, wagons and locomotives. The Mcclintock s Skinner Inc. train run/haul simulation programme can be described as follows :-

- it is capable of handling trains of any length over any combination of track geometry. 
TABLE 1

LOADING AND UNLOADINC DATA FROM OPERATOR'S LOG SHEETS

\begin{tabular}{|l|l|l|}
\hline ACTIVITI & MEAN RECORdEd TIME & $\begin{array}{c}\text { STANDARd DEviation } \\
\text { MiNuTES }\end{array}$ \\
\hline LOAD AT SHAFT A & MINUTES & 18,8 \\
LOAD AT SHAFT B & 43,5 & 21,1 \\
LOAD AT SHAFT C & 46,1 & 14,0 \\
UKLOAD AT PLANT A & 31,0 & 19,9 \\
\hline UNLOAD AT PLANT B & 46,3 & 21,7 \\
\hline
\end{tabular}

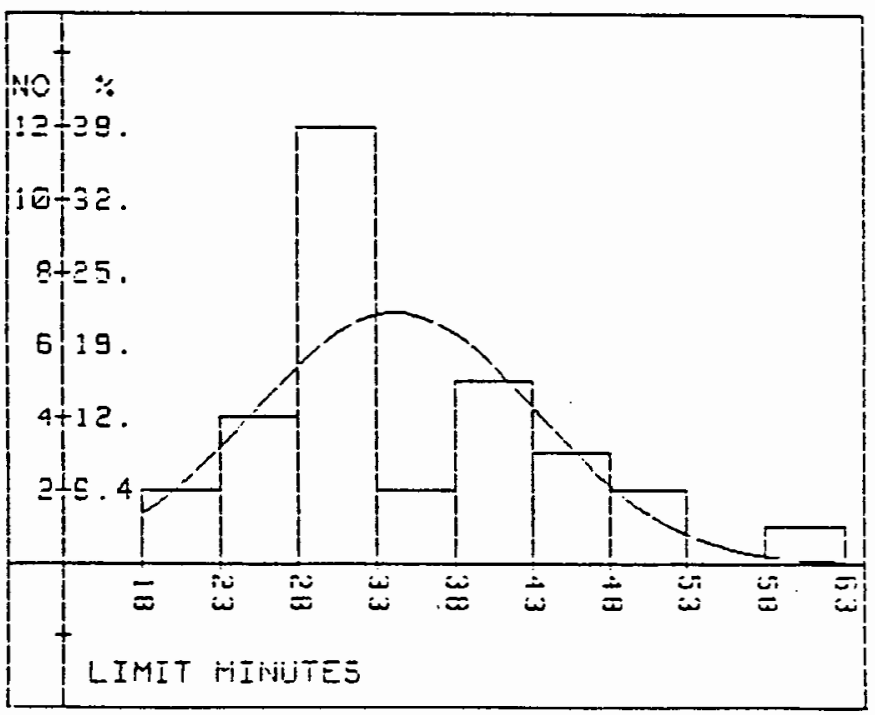

FIGURE 1 .

statistical analysis of train operator's logged times for full train haul from Shaft C to Plant B. 
- it is able to be used by persons with minimal computer experience.

- it yields results in an output format which can be understood by interested parties, such as Enginers, Managers of railway systems or Private Sidings, technicians, and by non-technical management.

- it produces results with an accuracy of between $5 \%$ and $10 x$.

\section{Train Simulation Methods}

The movement of a train between two points may be simulated either by average speed or finite increment methods. The former method involves dividing the route into sections over which an average speed can be assessed and then using this speed in calculating the time to traverse each section from the equation

$\mathbf{t}=\frac{\mathrm{s}}{\mathrm{v}}$

The finite increment method, can be used manisally for small models but-usually requires a computer and is described belok. A comparison of these methods is given in Table 2 .

TABLE 2

A COMPARISON OF THE ADVANTAGES AND disadVANTAGES OF 3 methods OF SIMULATING TRAIN HAULS

\begin{tabular}{|c|c|c|}
\hline METHOD & DI SADVANTAGES & ADVANTAGES \\
\hline $\begin{array}{l}\text { 1. MANUAL } \\
\text { AVERAGE } \\
\text { SPEED }\end{array}$ & $\begin{array}{l}\text { Requires experience in } \\
\text { assessment. Average } \\
\text { speed can give erroneous } \\
\text { values. }\end{array}$ & Quick results. \\
\hline $\begin{array}{l}\text { 2. MANUAL } \\
\text { FINITE } \\
\text { INCREMENT }\end{array}$ & $\begin{array}{l}\text { Time Consuming } \\
\text { Each increment must be } \\
\text { done separately. Only } \\
\text { suitable for simple short } \\
\text { hauls. }\end{array}$ & Accurate results. \\
\hline $\begin{array}{l}\text { 3. COMPUTER } \\
\text { FINITE } \\
\text { INCREMENT }\end{array}$ & $\begin{array}{l}\text { Time Consuming in data } \\
\text { preparation, especially } \\
\text { track geometry. }\end{array}$ & $\begin{array}{l}\text { Accurate results. } \\
\text { Data easily varied for } \\
\text { operational optimisa- } \\
\text { tion. }\end{array}$ \\
\hline
\end{tabular}




\section{Matheratical Theory \& Definitions}

The resistance of the train to motion is expressed as:

$\mathbf{R F}=\mathbf{R}+\mathbf{M} \mathbf{x}$

$R$ = The sum of the train resistance forces (Rolling, Grade and

Curvature)

Mt $=$ Total mass of the train

a acceleration of the train

The maximum tractive force that can be developed by the locomotive (asbuming the prime mover has oufficient pover in overcoming the resisting forces) is given by :

$$
\begin{aligned}
\mathrm{TE} & =\mathrm{M}_{1} \times \mathrm{g} \times \mathrm{f} \ldots \ldots \ldots \ldots \ldots \ldots \ldots \ldots \ldots \ldots \ldots \ldots \ldots \ldots \ldots \ldots \ldots \ldots \ldots \ldots \ldots \\
\text { where } \mathrm{TE} & =\text { maximug tractive effort } \\
\mathrm{H}_{1} & =\text { locomotive mass } \\
\mathrm{g} & =\text { acceleration due to gravity } \\
\mathrm{f} & =\text { coefficient of adhesion (which reduces as speed increases) }
\end{aligned}
$$

At any given moment these two equations are in equilibrium giving rise to the equality :

TE $=$ RF

By substituting equations 2 and 3 in 4 we get the acceleration of the train:

$$
a=H_{1} \times 8 \times f-R
$$

$$
\text { Mt }
$$

The power consumed by the locomotive is given by :

$$
P=\frac{T E \times V}{k} \cdots
$$

where TE $=$ Tractive Effort

$v \quad$ - The velocity of the locomotive

k = The locomotive effiency

The motion of the train is examined at the beginning and end of each pre-selected time interval using equations (7), 8) and (9).

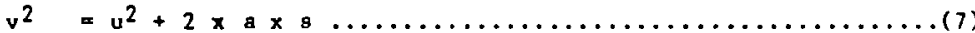

$$
\begin{aligned}
& \text { s }=u t+\frac{1}{2} \times t^{2} \\
& \mathrm{v}=\mathrm{u}+\mathrm{at} \\
& \text { Where } u=\text { initial speed at the beginning of a time period } \\
& v \quad=\text { final speed at the end of a time period } \\
& s \text { = distance travelled during selected time period }
\end{aligned}
$$




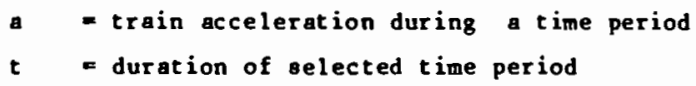

\section{Lipitations of the Theory}

The mathematical theory on wich the program is based has been simplified to make the program easy to use in a broad spectrum of applications including mine train haulages, light and heavy transit aystems and heavy haul railways. The theory does not include a vigorous approach to :

- the acceleration of rotating and reciprocating componente of the train.

- the variation of tractive effort and power with opeed (and boilex pressure in the case of stem).

- the loss of power in the wagon couplers.

Radial accelerations on curved track are ignored and non-linear motion is accounted for by the curve resistance component of $\mathrm{R}$.

\section{Computer Simulation Programe}

The programe simulates the progress of a train between two defined points by freezing it at consecutive pre-selected time intervals starting from zero. Certain train and track characteristics are required in order to perform the necessary calculations and must be provided as input data.

\section{The Geowetric Data}

- longitudinal section complete with horizontal and vertical aligment over wich the haul is to be simulated.

- Portions of the route over which speed restrictions will apply.

- maximum allowable speed on the line.

\section{The train data}

- total mass of a typical wagon.

- total number of ragons.

- wagon bearing and bogie type.

- effective traction mass of the locomotive/s.

- total mass of the locomotive/s.

- rated power of the locomotive/s for traction. 


\section{Programe default dat a}

Typical values of resistances, adhesion, etc. have been built into the programe and the user must select a wagon bearing and bogie type to define the characteristic resistances. The bearing type defines the rolling resiatance, while the bogie type defines the the running characteristics. Whether or not the wagon is equipped with Scheffel bogies, is a factor wich effecto the curve resistance.

\section{Train simulated run}

With the input of the above data completed the programe is ready to simulace the progress of the train. A basic flow chart of the program is given in Figure 2. The simulated train is placed on the defined long section and its resistance is calculated on the basis of the track geometry data taking into account the length and mass of the train. The acceleration "a" is calculated using equation (5) and the distance and speed at the end of the defined period calculated. With the train in the new position, the procedure is repeated. This method assumes that the acceleration at the beginning of a time period is valid for the duration of the period.

The power consured is the last calculation in each cycle. If this exceeds the rated power of the locomotive's prime mover, the programme will reduce the speed at the end of the current time period until the power consumed is reduced to the maximum available. The distance moved by the train is then re-calculated.

Speed restrictions are catered for by monitoring the position of the train en-route against the locations where restrictions are applicable. Upon approaching a speed restricted section a characteriatic deceleration is applied to reduce the simulated crain speed. It commences at a calculated point prior to the restricted zone so as to decelerate the train timeously. The speed at the end of each time interval is monitored against the speed restriction and when the $r$ atio of the two reaches an acceptable value the deceleration is removed. When the simulaced train leaves a restricted section it accelerates at maximum power until the new ruling speed is attained. As the simulated train approaches the end point it is decelerated at a 


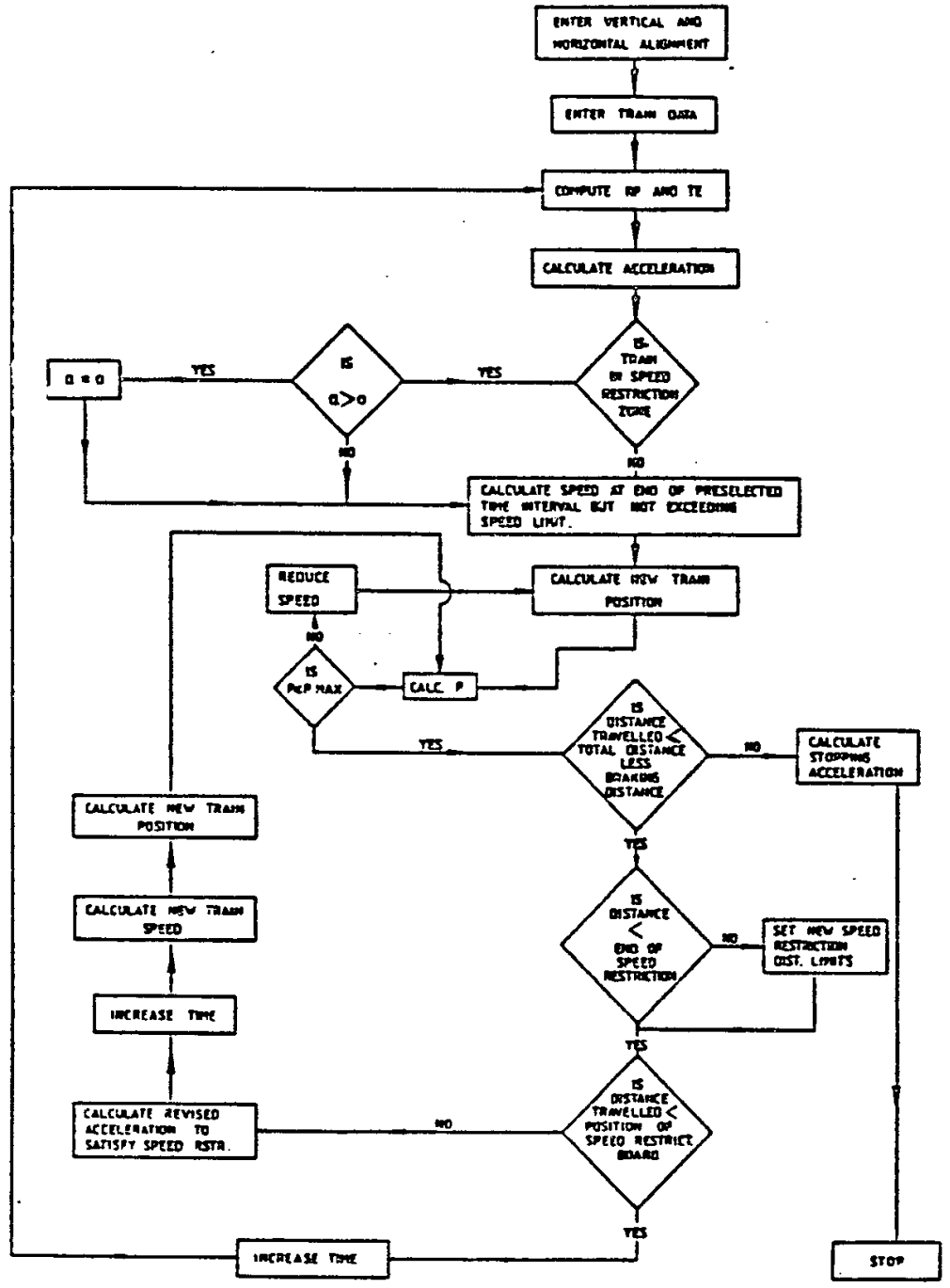

FIGURE 2

FLOH DLAGRAM OF SIMULATED TRAIN HAUL PROGRAM STRUCTURE 
characterstic rate until stationary.

\section{Printout of Results}

The print out includes the time and distance elapsed, and the velocity acceleration and average power demand for the period in question together with the total distance travelled, time taken and power consumed. The option of drawing velocity time and distance time graphs is also available to the user.

\section{Discussion}

It has been found that the use of a typical time interval of 1 second for analysis, yields results that are within $\pm 7 \%$ of actual recorded train haul times. Greater interval durations produce unsatisfactory results. Time intervals of less than one second, while yielding slightly more accurate results, use excessive computation time which does not justify the increase in accuracy.

The reasons for the discrepency between actual and simulated times could be :-

- binding brakes, sticky centre-plate bearings on bogies, damaged bearings and wheels

- temporary loss of traction when passing over turnouts or poorly maintained track and is not modelled.

\section{NETWORR SIMULATION}

\section{Method of analysis}

Two methods of analysing the railway system, manual and computer, vere considered.

The manual basically involves the plotting of time-distance graphs of the train movements in the system. If it is found that more than one train has to run in a track section in order to meet the schedule then additional tracks will be required. The advantages of this method for simpler systems are :

(i) they are easy to produce.

(ii) they are readily understood. 
The disadvantages are :

(i) the diagram is rigid and specific to the conditions modelled and if any of them need to be changed a new diagram must be drakn.

(ii) the diagrams on a complex or busy system become difficult to draw and to interpret.

(iii) the development of operating statistics from the diagram is time consuming and open to random errors.

(iv) the high draughting and plotting content makes the method prone to inaccuracies.

Computer models can be written using a formal primary language such as Basic, Fortran and Pascal, or one of the many the specialised simulation modelling languages such as HOCUS, SLAM, and GPS. The advantages of computer models are :

(i) they are relatively simple to produce using the specialised 1 anguages.

(ii) once the model has been validated, the results are consistently accurate and as reliable as the input data.

(iii) the required statistics are available as soon as a model has run.

(iv) changes $c$ an be made to the input data and the model structure to a greater or lesser degree depending upon the language.

(v) the parameters can be changed as often as necessary to optimise the prototype being modelled.

The disadvantages are :

(i) specialised programming knowledge is required.

(ii) no results are obtained until the model is complete and validated. This is often only after 90 percent of the manpower budget for the exercise has been expended.

The computer model approach was adopted because of the complexity of the rail system and the need to study different traffic levels and vary the routes.

\section{HocuS Simulation Language}

We used the HOCUS simulation language for modelling the system. Hocus is a mnemonic for Hand Or Computer Universal simulator and, as the name implies, the models can be run by hand or a computer. Hand simulation is only effective for small models or proving the logic of 
The Hocus language, through the medium of the hand model is also highly effective as a visual aid in illustrating how the model works to clients, managers and engineers. This language is almost unique in this respect, and it can produce a high level of client confidence and participation in the modelling process.

The basic structure of a Hocus model is very simple consisting of entities, activities and queues.

(i) Entities are resources such as men, locomotives, wagons, tracks, passing loops, loadouts, conveyors, silos, pipes, pumps, tanks, work shifts, tools, maintenance teams, workshops, seasons of the year, ocean tides, storms, meteorites, planets, radio active material, etc. The list is as endless as creation.

(ii) An activity is the state in which an entity remains, either on its own or with other entities while a specific operation or process takes place over a period of time. The time may be constant or variable and once started the activity will continue until the time is complete, unless the logic of the model allows it to be interrupted. Activities can have alternative conditions allowing a decision process to take $\mathrm{place}$ in the selection, source and destination of entities. Activities can be discrete or continuous within the same model. An activity of a higher prioricy can interrupt a continuous activity if they both require the same entity.

(iii) A queue is the state, and location in the model, in which an entity awaits the start of an activity. At the beginning of every model run, all entities must be in a queue. A queue $c$ an have more than one entity and different types of entities can be placed in the same queue. The positions in which entities are placed in and drawn from queues can be manipulated. It is sometimes convenient to use a queue in the place of an entity when modelling a storage vessel or location.

A Hocus simulation model is therefore a continuously changing flow diagram which shows the active and idle states of entities as time progresses. An entity spends its 1 ife in a sequence of activities (active state) and queues (idle state). Entities must always move from 
queue to an activity and from an activity to a queue, but never from activity to activity or queue to queue. The time that an entity spends in a queue can be, and often is, zero.

In modelling real situations it is necessary for resources to be idle so that parts of the system can be independently active during certain time periods without affecting other parts. An example of this is the hoisting of ore from underground, which is independent of the trains that transport the ore, providing there is sufficient space in the silo (entity or queue) between the conveyor and the train.

From the above description the HOCUS language may appear to be simplistic, but its sophistication and porer lie in the manipulation of entity attributes through attribute options.

\section{(iv) Attributes}

An attribute of an entity is any property or characteristic of the entity which influences or measures its behaviour. For example an attribute may be used as a clock to record the time an entity spends in some part of its life cycle. It may represent a quantity such as the fuel in a locomotive or the quantity, or type, of ore in a wagon. It may indicate the next machine to breakdown, show to which machine a worker should proceed or be a measure of a delivery's priority. In fact, any property that can be expressed as a positive integer can be defined as an attribute. Each entity can have up to 20 attributes, and any attribute can be given a maximum value which will not be exceeded.

Further examples of attributes are:

- the cost of a product, process or service

- the rate of flow along a pipe

- the condition of a patient

- the grade of a product

- the driver of a lorry

- the number of items a machine produces before it has to be reset

- the temperature of a chemical.

Attributes in themselves are of little use unless the modeller is able to manipulate them in various ways. This is accomplished using options. 


\section{(v) Opt ions}

In a real life situation many properties of entities vary frequently in magnitude and location. These changes are brought about in the model through the options feature. We may wish to accomplish the following :

- transfer the contents of a truck into a bunker

- route passengers through an airport terminal

- match a customer order against produce in stock

- check the contents of a vessel

- calculate the total stock in a number of silos

- calculate the cost of a process, delays or maintenance

- record values in a histogram.

HOCUS has 99 standard options which fall into 11 groupings :

- transfer

- match, compare and copy

- attribute alteration

- attribute checking

- attribute arithmetic

- queue size options

- queue position options

- data base facilities

- attribute histograms

- variable percentages

- out put reports

On rare occasions the attribute manipulation is too complex to use the standard forms. For this purpose a 12 th category permits the user to write his own "special sub-routines and functions" to accomplish, for example:

- calculate the duration of an activity

- print non-standard output reports

- collect non-standard statistics about the model

- mainipulate queue contents

- interrupt activities before their normal end time

- update attribute value

- specify complex logic. 


\section{HOCUS MODEL OF THE MINE RAILWAY SYSTEM}

of the four shafts, three supply reef to the three remote reduction works. The fourth shaft supplies reef only to the adjacent reduction works by conveyor. The reef is stored in silos above the railway tracks for subsequent loading into trains which $t r a n s p o r t$ the reef to the reduction plants. The silo capacities at each shaft differ, but the train payloads are constant. In order to maintain steady production it is therefore more critical to provide a train for loading reef timeously at the shaft with lowest silo capacity than at the others. A scheme layout of the mine rail system as modelled is shown in Figure 3.

The system operation has six basic train routes with trains staging at Plant $B$ whilst awaiting a load. These are (with reference to Figure 2) :-

1. Plant B - Shaft A - Plant A - Plant B.

2. Plant B - Shaft B - Plant B.

3. Plant B - Shaft B - Plant A - Plant B.

4. Plant B - Shaft C - Plant B.

5. Plant B - Shaft C - Plant C - Plant B

6. Plant B - JosHUA - Plant B.

In the case of the route to shaft $C$, trains do not return after unloading until the end of a shift or for refuelling. They wait close to the main line at EXOPLB and have priority over empty trains waiting in PLANT $B$ in being called to load at one of the shafts.

\section{Activity Precedence}

In Hocus activities run in numerical sequence of activity numbers. In the model described, activities involving laden reef trains are given precedence over those with empty reef trains wich in turn have priority over manganese train activities. Trains ahead in each of the laden and empty phases of the model have precedence over trains behind, whether they are carrying reef or manganese. This approach is realistic and safe but not essential as the model logic ensures that it cannot become blocked. This is described below.

\section{Model Activity Logic}

On a single line railkay system trains can only cross or pass each other at passing loops which can each accomodate a full length train. To 


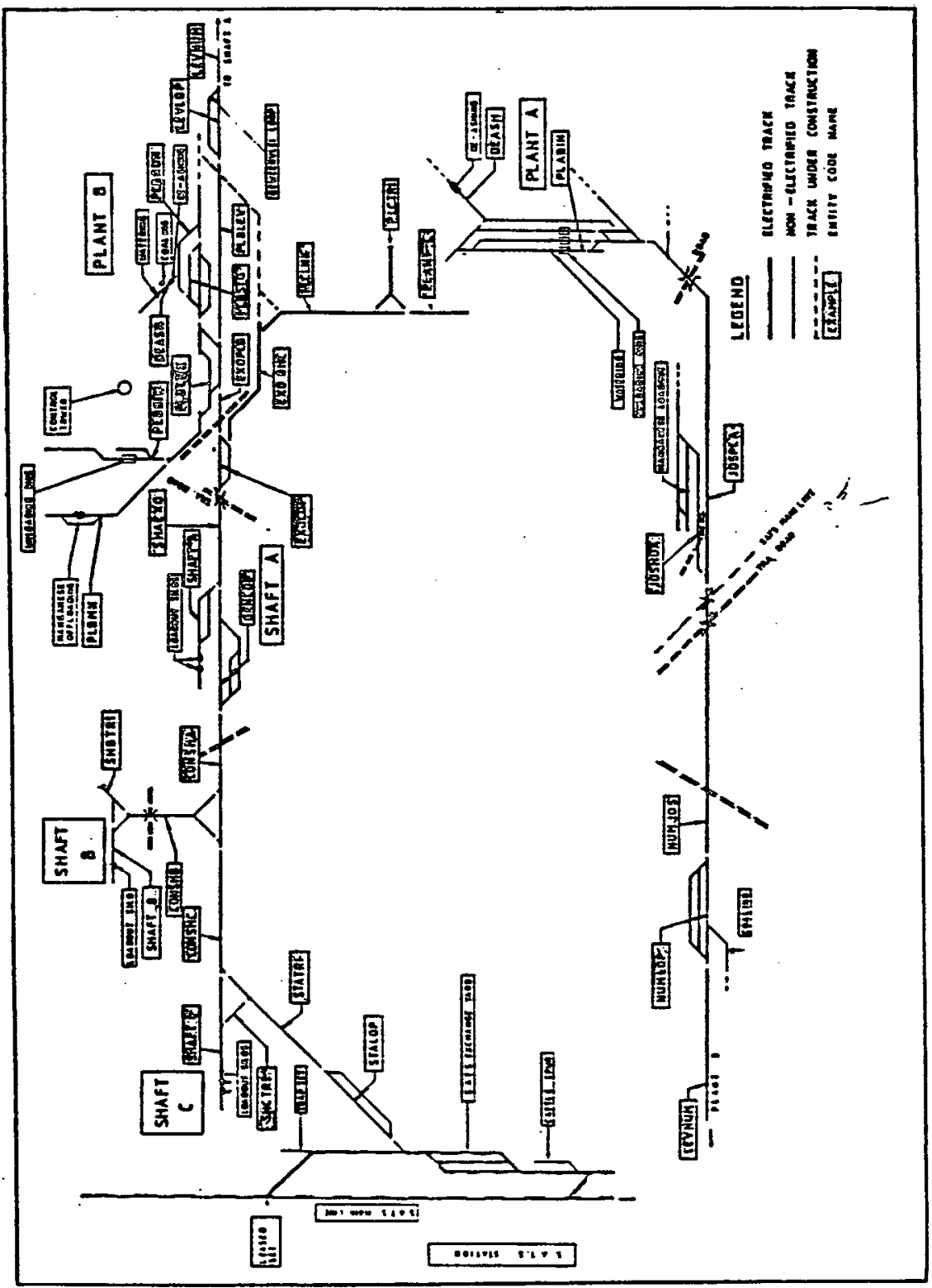

FIGURE 3

SCHEMATIC LAYOUT OF MINE RAILWAY SYSTEM SHOWING TRACK ENTITY CODES 
ensure that a collision between two trains cannot occur, all sections of track between passing loops and one track in the passing loops at each end, is allocated to only one train at a time. A train therefore runs from loop to loop, releasing the tracks behind it as it clears that section.

Usually only one track section exists between passing loops, but an exception occurs when a branch line runs off between the loops. In this case two sections of track are modelled one on each side of the branch, so that a train travelling in one direction can release the cleared section of track to a train wishing to travel into the branch line, or out of it in the opposite direction to the first train. An example of the situation exists between GENLOP and SHAFTC where the branch line CONSHB divides the section into CONSHC and CONSHA (Figure 3 ).

\section{Train Generation Logic}

Two different model situations were run, one to establish the maximum amount of reef that could be moved by the railway system, and the other with a predetermined train schedule to optimise the resource requirement and utilizations at the design throughput level.

In the first case a record was kept of the amount of reef in each silo in the " $A$ " attributes of the entities SHAFTA, SHAFTB and SHAFTC representingthe 3 shafts with loadouts. Constants equal to a percentage of the full train reef capacity was stored in their " $B$ " atcributes. The percentage varied for each shaft and was inversely proportional to the silo filling rate and the time for a empty train to travel to the loadout. The " $\mathrm{C}$ " attributes vere used as a counter and had an initial value of 1 . When the quantity of ore in a silo (" $A$ " attribute) exceeded the product of the modified train capacity (" $B$ " attribute) and the " $C$ " attribute, a train would be sent for loading. The " $\mathrm{C}$ " attribute would immediately be increased by 1 at the beginning of the activity to prevent another train from being sent. When the train was loaded, the loadout " $A$ " attribute would be reduced by the capacity of the train and the " $C$ " attribute by 1 .

In the second case a schedule was prepared, using information obtainedfrom the first simulation to direct trains to the six routes and 
the desired tonnage evenly throughout the day.

\section{Systen Breakdouno}

System breakdowns of the shafts, loadouts, trains and locomotives were not simulated as insufficient information was available. The hocus language allows random breakdowns of varying rates to be simulated where the data is available.

In the case under reviek we derived nett utilizations expressed as a percentage of availability, the latter being reduced below $100 \mathrm{z}$ in accordance with our experience for railway system of this type.

\section{Sirulation Results}

The times that locomotives, wagons, loadouts, offlosding bins and tracks were in use were recorded by atribute clocks. These can be switched on or off at the beginning or end of activities. Each value of an attribute can be recorded and a histogram produced.

The contents of queues are recorded each $t$ ime they vary and Q-Logs can be obtained. A typical example is given in Figure 4 wich records the idle time of locomotives. From a knowledge of the programe this histogram reveals that the maximum number of locomotives used was 5 as they 811 have to 8 tart and end at queue 22 , and that the utilization was therefore $54 z$ of total time.

\section{Coneluoions}

The results of the train haul simulation model are validated by the close correlation to those obtained from observations of the prototype.

The *HOCUS simulation model provided information which was used to determine the numbers of locomotives, trucks and tracks required at the Mine for the existing and proposed tonnages. *hocus provides a powerful means of modelling life cycles of many forms and can provide quantitative information for design purposes. 
http://orion.joufpals.ac.za/

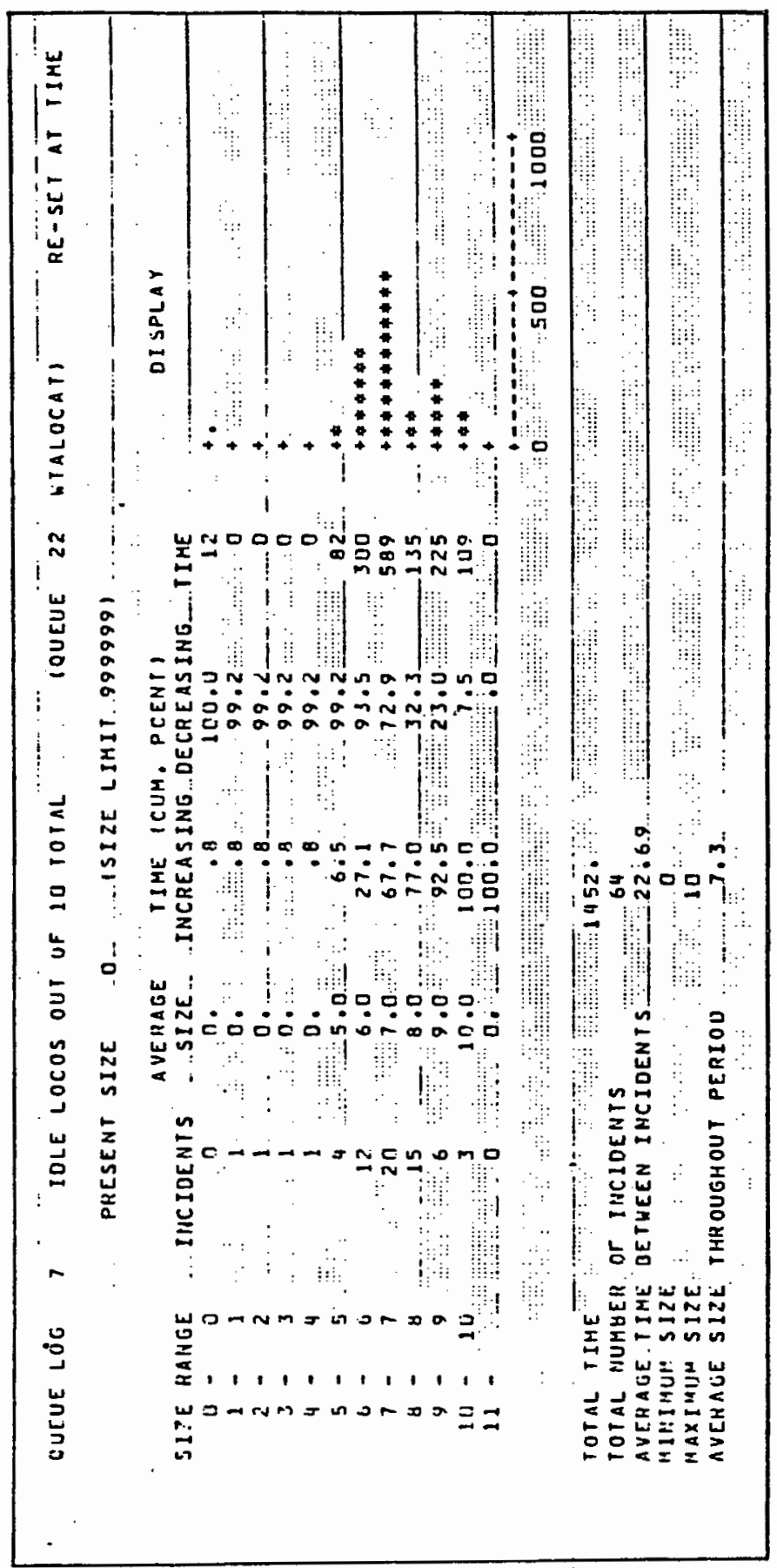

FIGURE 4.

Histogram of idle locomotives out of 10 in queue 22 . 


\section{ACRNCANLDDGBAENTS}

Our thanks are extended to P.E. Corporate Services and Computer Sciences

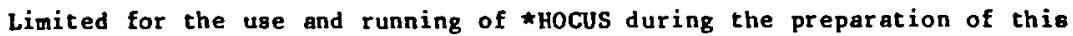
paper.

\#HOCUS - "HAND OR COMPUTER UNIVERSAL SIMULATOR" Ianguage, developed and copyright held by P.E. Corporate Services, Park House, Egham, Surrey, United Ringdom. 